MATEC Web of Conferences 22,03019 (2015)

DOI: $10.1051 /$ matec conf/ 20152203019

(C) Owned by the authors, published by EDP Sciences, 2015

\title{
Finite Element Analysis of Moving Platform Based on ANSYS Work- bench
}

\author{
Hanyuan $\mathrm{Hu}$ \\ Department of Mechanical Engineering Changchun, Changchun University of Science and Technology, Chang- \\ chun, Jilin, China \\ Lizhong Zhang * \\ Fundamental Science on Space-Ground Laser Communication Technology Laboratory, Changchun, Jilin, China
}

Yangyang Bai \& Jin Hong

Department of Mechanical Engineering Changchun, Changchun University of Science and Technology, Changchun, Jilin, China

\begin{abstract}
The thickness and rib layout of the moving platform which is a part of 2-DOF motion platform is the main factor affecting the performance of it. This initial design scheme was analyzed by making the use of ANSYS Workbench, which controls the maximum deformation and maximum stress in the range of permission. The quality of the platform could be reduced by $35.4 \%$; the lightweight analysis and the modal analysis were made for the platform, and had obtained inherent frequency of the platform. The holes with quadrilateral shape were adopted to ensure that the platform could have enough stiffness and stability.
\end{abstract}

Keywords: 2-DOF motion platform; ANSYS Workbench; lightweight analysis; modal analysis

\section{INTRODUCTION}

For the long distance laser communication, the carrying platform's attitude change is the main environmental factors affecting the performance of the APT system of optical terminal ${ }^{11}$. We should simulate experiment by using 2-DOF platform of which imitated the carrying platform's attitude change. Therefore, we could ensure the accuracy of results in the laser communication optical terminal's performance test. Because the gravity center of optical terminal did not coincide with the center of platform, the alternating loads were generated by the inertial load which directly exerted on a platform during the movement. Therefore, the structural rigidity would impact the life of moving platform and movement accuracy directly. So it would be necessary to analyze the platform in order to obtain higher stabilization accuracy and kinematic accuracy. And the weight of motion platform was less than $50 \mathrm{~kg}$ in requirement. Then the weight has to be reduced on the premise of ensuring the strength and stiffness.

\section{INTRODUCTION OF MOVING PLATFORM'S STRUCTURE}

By stabilizing the optical terminal on the moving platform, it simulated the attitude change on board by controlling three electric cylinders' telescopic motion of the azimuth and elevation. The moving platform and middle supporting platform were connected by

*Corresponding author: zlzcust@126.com frame structure. This scheme not only increases space to install equipment, but decreases the height of equipment's center of gravity to improve the equipment stability as well. It reduced the size of the motion platform then lightened the weight of the whole platform on the premise of which meets the demand of enough stiffness. The structure of motion platform was shown in Figure 1:

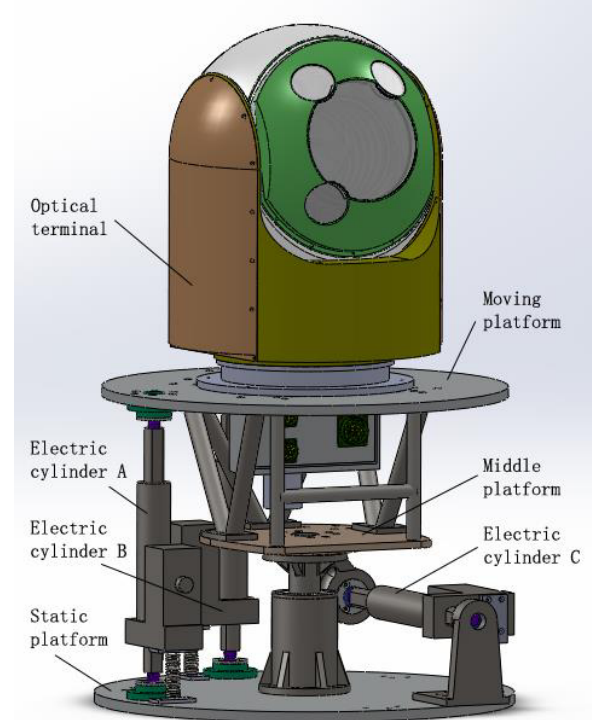

Figure 1. Structure of motion platform

This is an Open Access article distributed under the terms of the Creative Commons Attribution License 4.0, which permits unrestricted use, distribution, and reproduction in any medium, provided the original work is properly cited. 


\section{MATEC Web of Conferences}

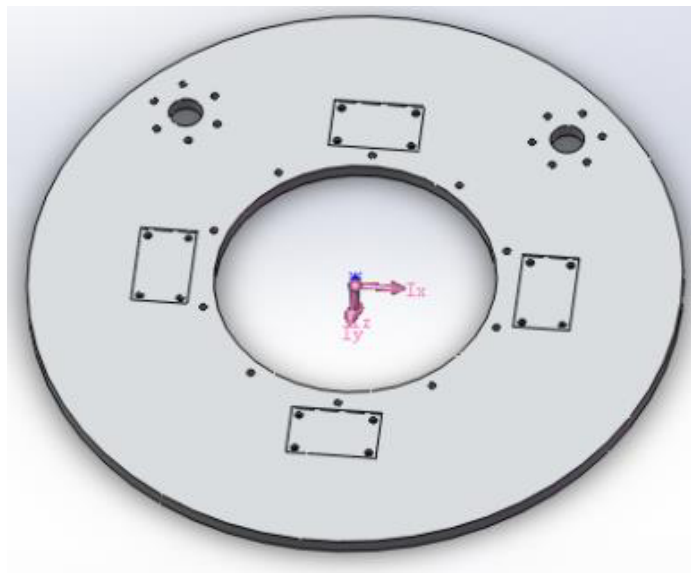

Figure 2. Structure of moving platform

The moving platform was designed as a shape of circle structure because the optical terminal was installed on it. As shown in Figure 2, this design could be convenient to support the optical terminal, meanwhile, reduce weight and save material in order to decrease the requirement for the electric cylinder. The platform is connected with the electric cylinder through a spherical hinge which was added on the foundation bed to ensure the stiffness.
3 RESEARCHES ABOUT MODELING ANALYSIS OF MOVING PLATFORM

\subsection{Mesh subdivision and modeling analysis}

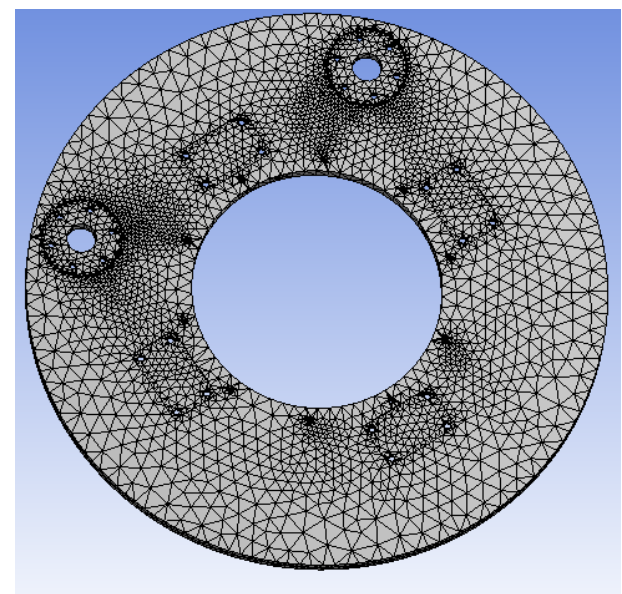

Figure 3. Mesh subdivision of moving platform

According to the requirements of the platform's structure, the model was established as the actual size by geometric modeling module in ANSYS Workbench. The load of 2-DOF motion platform was about $60 \mathrm{~kg}$; the external diameter of platform was $580 \mathrm{~mm}$, and the inside diameter was $250 \mathrm{~mm}$; the material was aluminium alloy; the density was $2780 \mathrm{~kg} / \mathrm{m}^{3}$; the elastic modulus was $0.72 \times 10^{5} \mathrm{MPa}$; Poisson's ratio was 0.33 .

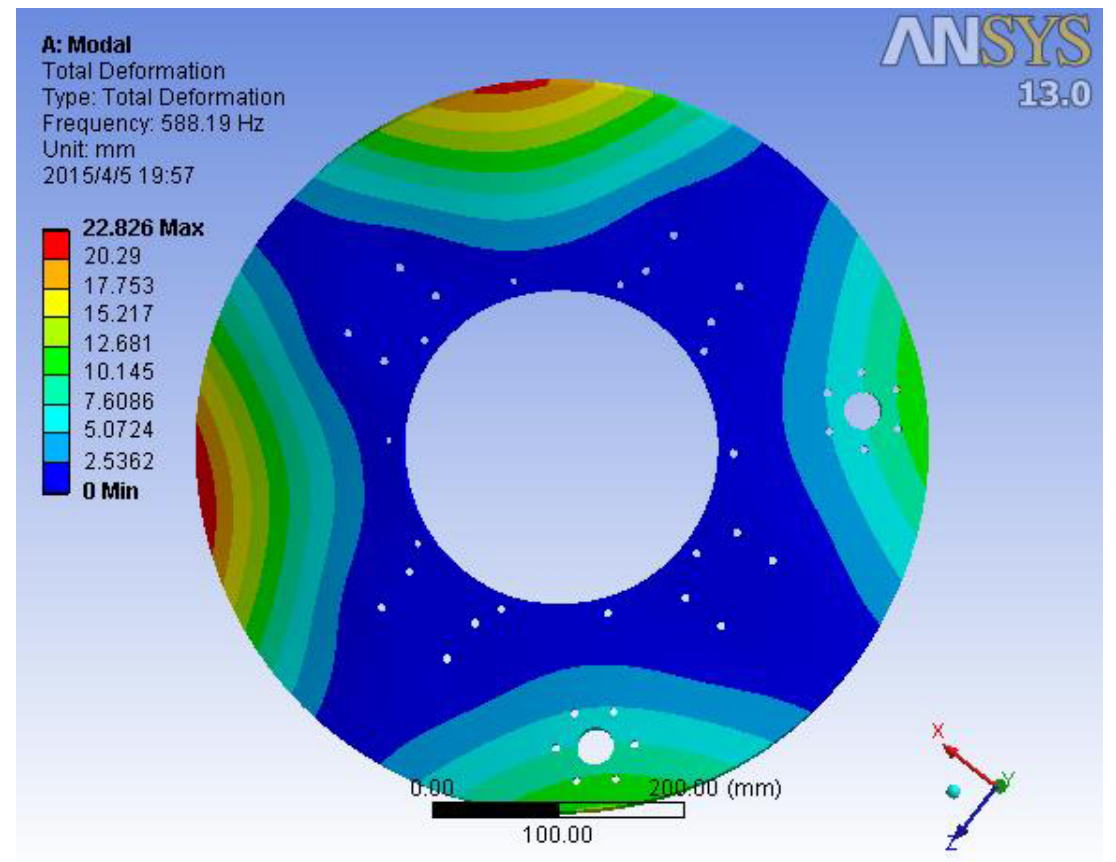

Figure 4. Vibration mode of the First order mode of moving platform 
ICETA 2015

Table 1. Inherent frequency of the moving platform

\begin{tabular}{|l|l|l|l|l|l|c|}
\hline Modal order & 1 & 2 & 3 & 4 & 5 & 6 \\
\hline Frequency $(\mathrm{Hz})$ & 588.19 & 606.84 & 610.21 & 629.4 & 1023.5 & 1068.1 \\
\hline
\end{tabular}

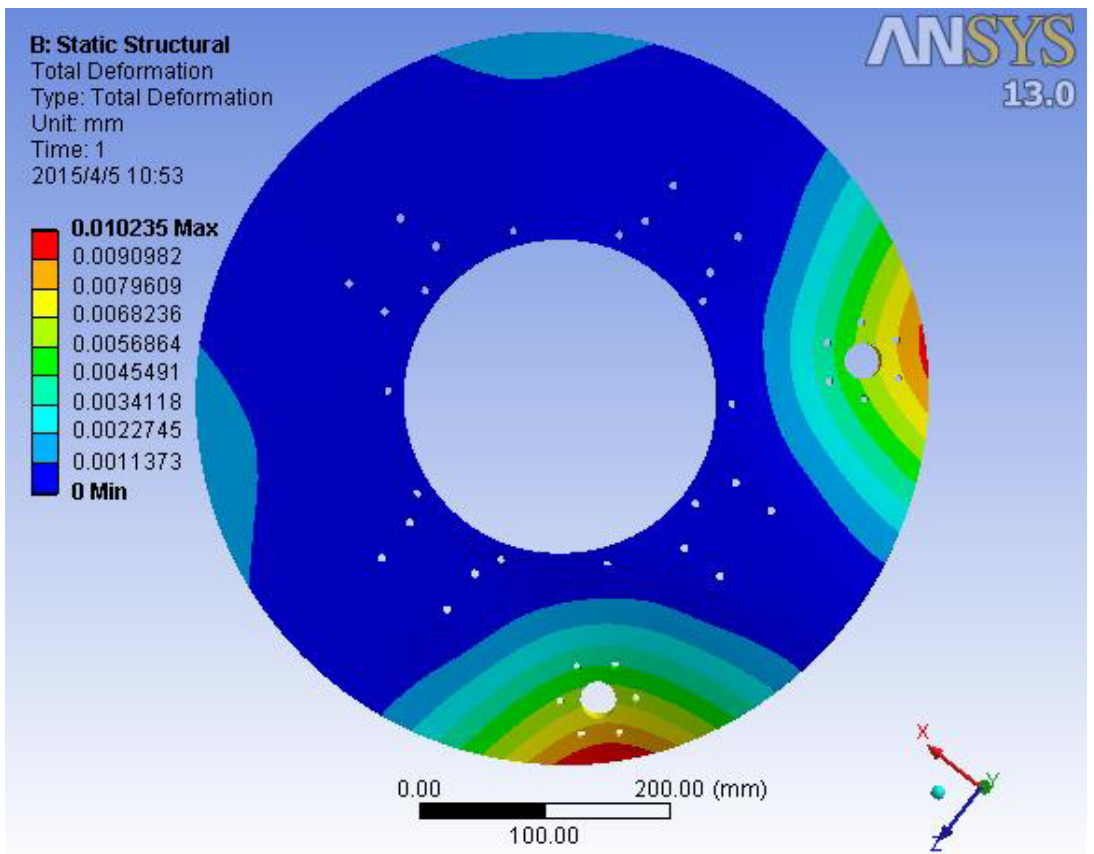

Figure 5. Deformation of moving platform

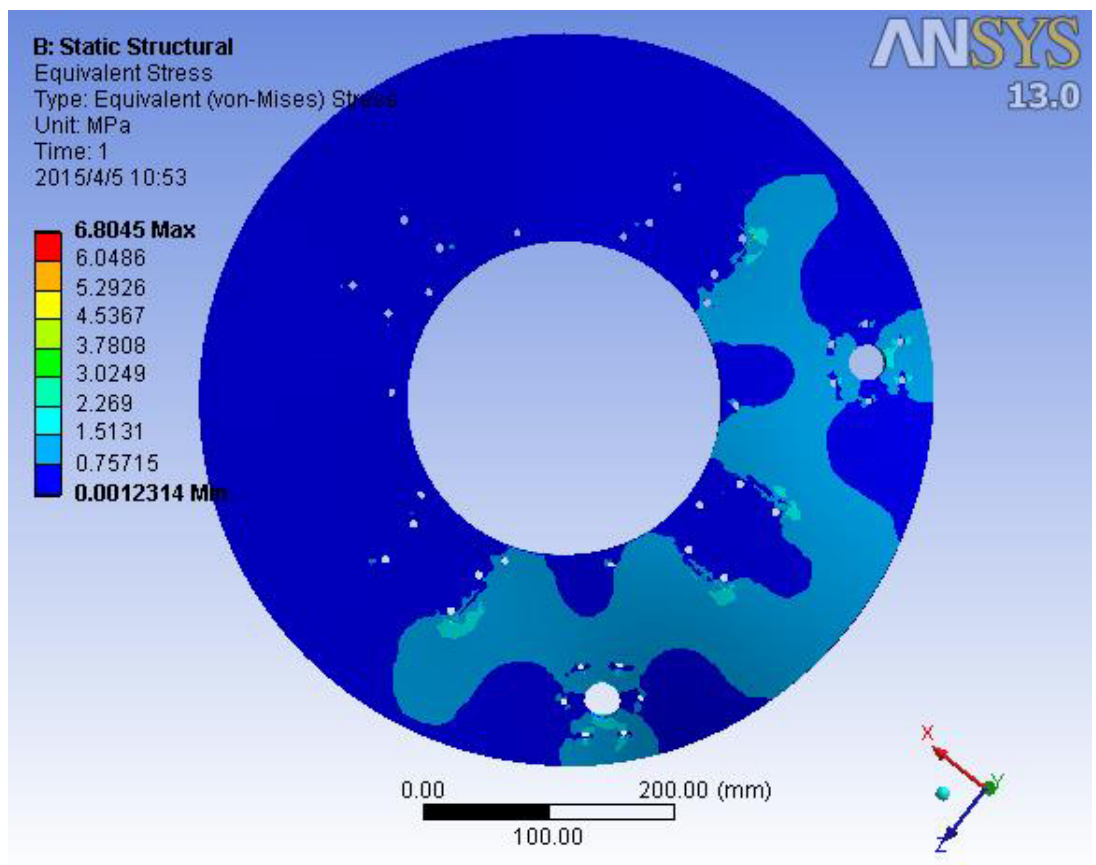

Figure 6. Stress distribution of moving platform 


\section{MATEC Web of Conferences}

Table 2. Analysis results of different thickness

\begin{tabular}{|l|l|l|l|}
\hline Thickness & Maximum stress $(\mathrm{MPa})$ & Maximum deformation $(\mathrm{mm})$ & Weight $(\mathrm{kg})$ \\
\hline 14 & 3.80 & 0.011 & 7.915 \\
\hline 13 & 3.785 & 0.012 & 7.341 \\
\hline 12 & 3.98 & 0.015 & 6.768 \\
\hline 11 & 4.48 & 0.020 & 6.194 \\
\hline 10 & 5.64 & 0.026 & 5.621 \\
\hline
\end{tabular}

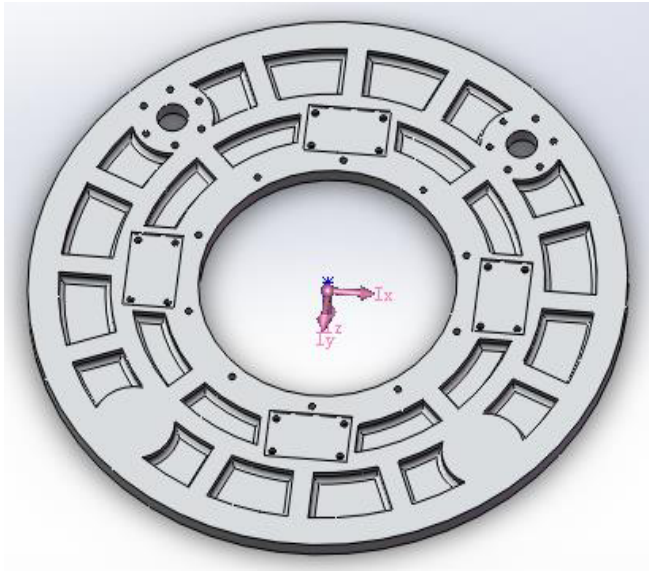

(a)

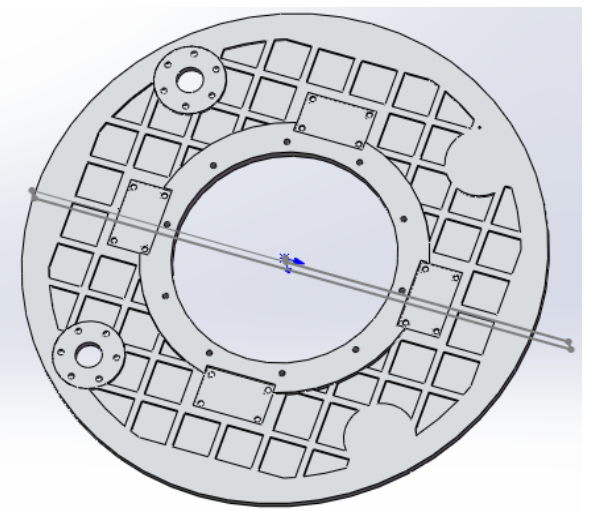

(b)

Figure 7. Structure of Structure

Table 3. Comparison of two kinds of structure

\begin{tabular}{|l|l|l|l|}
\hline & Weight $(\mathrm{kg})$ & Maximum deformation $(\mathrm{mm})$ & Maximum stress $(\mathrm{MPa})$ \\
\hline Structure 1 & 5.470 & 0.055 & 5.578 \\
\hline Structure 2 & 5.113 & 0.034 & 7.219 \\
\hline
\end{tabular}

Table 4. Inherent frequency of the up-platform

\begin{tabular}{|l|l|l|l|l|l|l|}
\hline Modal order & 1 & 2 & 3 & 4 & 5 & 6 \\
\hline $\begin{array}{l}\text { Frequen- } \\
\text { cy }(\mathrm{Hz})\end{array}$ & 384.59 & 392.96 & 393.82 & 401.65 & 616.91 & 658.86 \\
\hline
\end{tabular}

The established model was imported into a finite element analysis module of ANSYS Workbench. The moving platform was meshed in Automatic method. As shown in Figure 3, it consists of 54835 nodes and 30547 units.

As shown in Table 1, the inherent frequency of moving platform was known by modal analysis. The vibration mode of the first order mode was the edge of the board, the larger deformation was (which the vibration's directions in relative direction were the same), the more opposite vibration's directions in adjacent direction were. The moving platform was shown as a saddle. As shown in Figure 4, the amplitude is $22.83 \mathrm{~mm}$ in $588.19 \mathrm{~Hz}$.

\subsection{Stress constraint}

Due to the moving platform and the middle platform which are solid coupling, the displacement between any two points belonging to each platform didn't change. The solid coupling could be regarded as welding process which the moving platform was treated as the reference coordinate system. So the middle platform could be simplified to an inertial force to the moving platform. For the convenience of study, the ball joint bearing was simplified to force and rotational torque. The rotational torque could be ignored because of having no effects on deformation on the platform. The load that the moving platform suffered from the optical terminal was applied on surface where the optical terminal was connected with the moving platform in the form of surface load. The electric cylinder had driven the moving platform to simulate the posture. The load which the moving platform suffered from electric cylinder was applied on the contact with the spherical hinge in the form of surface load. The weight of moving platform was directly calculated in the finite element analysis according to the characteristics of the platform and automatically applied on the platform.

\subsection{Results of finite element analysis}

As shown in Figure 5, the maximum deformation of 
the moving platform was $0.01 \mathrm{~mm}$ through the finite element analysis on the moving platform. Figure 6 described the stress distribution of moving platform when the largest Von Mises equivalent stress under load. Allowable stress of moving platform was $25 \mathrm{MPa}$ [2]. The picture showed that the maximum operating stress under load is $6.8 \mathrm{MPa}$ which was less than allowable stress. Safety factor of moving platform was 3.68 , which is very safe. Therefore, it was necessary to design lightweight platform reasonably.

\section{LIGHTWEIGHT DESIGN OF MOVING PLAT- FORM}

It could be seen from the above analysis that the structure of moving platform was excessively reliable, so a lightweight scheme was designed to reduce the weight of the platform. Its preliminary determined thickness is between $10 \mathrm{~mm} \sim 14 \mathrm{~mm}$. As shown in Table 2, it listed the analysis results of different thickness on the platform when loading according to the different parameter modeling.

Because the gravity center of optical terminal didn't coincide with the center of platform, the alternating loads were generated by the inertial load which is directly exerted on a platform in the movement Therefore, the structural rigidity had a direct impact on life and movement accuracy, and the maximum deformation should be less than $0.060 \mathrm{~mm}$. It was determined the thickness of moving platform as $11 \mathrm{~mm}$ through comparing and analyzing different parameters of the model .

Lightweight was the removal of the material from the original structure on the premise of guaranteeing or improving structure rigidity. Holes' shapes after lightweight were triangular, quadrilateral, hexagon, honeycomb, fan-shaped and circular [3]. Different shapes had different processing properties and structural stiffness. The structural stiffness of honeycomb hole was superior to other shapes of holes [4]; the technological property of circular hole which removed material easily was best, but lightweight efficiency was lower. The fan shape structure was often used in the parts of lightweight which the structure center was a hole. It could have different effects by changing hole's shape.

As shown in Figure 7, this paper compared two structures through analysis. Structure 1was the moving platform which a lightweight hole was the shape of fan, structure 2 is the moving platform which a lightweight hole was the shape of quadrilateral.

As shown in Figure 3, through making use of ANSYS Workbench to analyze two kinds of structure, it obtained the maximum deformation and maximum stress of the structures under load and provided a theoretical basis for selecting,. Table 3 shows the comparison of two kinds of structure after lightweight.

The weight of moving platform was greatly reduced. The weight of structure 1 was reduced by $30.9 \%$, but the stiffness of structure 1 wasn't enough because of reducing weight which the maximum deformation was close to allowable deformation. The weight of structure 2 was reduced by $35.4 \%$, which was lighter than structure 1 , but the maximum deformation and maximum stress was far less than allowable. Therefore, structure 2 was chosen as the lightweight structure.

\section{MADAL ANALYSIS}

The modal analysis is a technology to calculate the structure's vibration characteristics. Vibration characteristics include inherent frequency and mode of vibration, which could have affected certain main order modal's characteristic in the frequency domain easily and predicted actual vibration response of the structure in this frequency domain based on the action of external or internal vibration source. Mode of vibration could be predicted under different load.

The modal analysis includes inherent frequencies and mode shape of corresponding vibration which can show the structure's vibration mode intuitively in order to identify the weak point. It could provide theoretical basis for improving the performance of structure.

The first order modal inherent frequency of moving platform is reduced down to $389.59 \mathrm{~Hz}$ after lightweight, because the inherent frequency of optical terminal is $100.62 \mathrm{~Hz}$ [5], and most of the inherent frequency of the aircraft below $100 \mathrm{~Hz}$ [6]. Due to the motion platform imitating aircraft vibration, the first order modal inherent frequency of moving platform should be three times more than inherent frequency of plane to avoid the vibration. Therefore, the moving platform which was after lightweight meets requirement of inherent frequency [7]. Avoid the moving platform being worked in the frequency domain of Table 4, because the resonance in lower frequency domain and harmful mode shape had great influence on the precision of moving platform.

According to the result of modal analysis, Figure 7 shows that mode of vibration of the platform was similar as the mode of vibration before lightweight, and the maximum deformation was $23.78 \mathrm{~mm}$ in the first order modal, which is close to deformation before lightweight. The maximum deformation didn't increase as cutting the thickness and weight down. It met the requirements even though the inherent frequency is decreased. Therefore, the scheme for lightweight was feasible.

\section{CONCLUSION}

(1) This paper had optimized parameters of structure by regarding the minimum of up-platform's quality as a optimization goal on the premise of ensuring stiffness and stability of platform.

(2) The analysis result had shown stress and defor- 


\section{MATEC Web of Conferences}

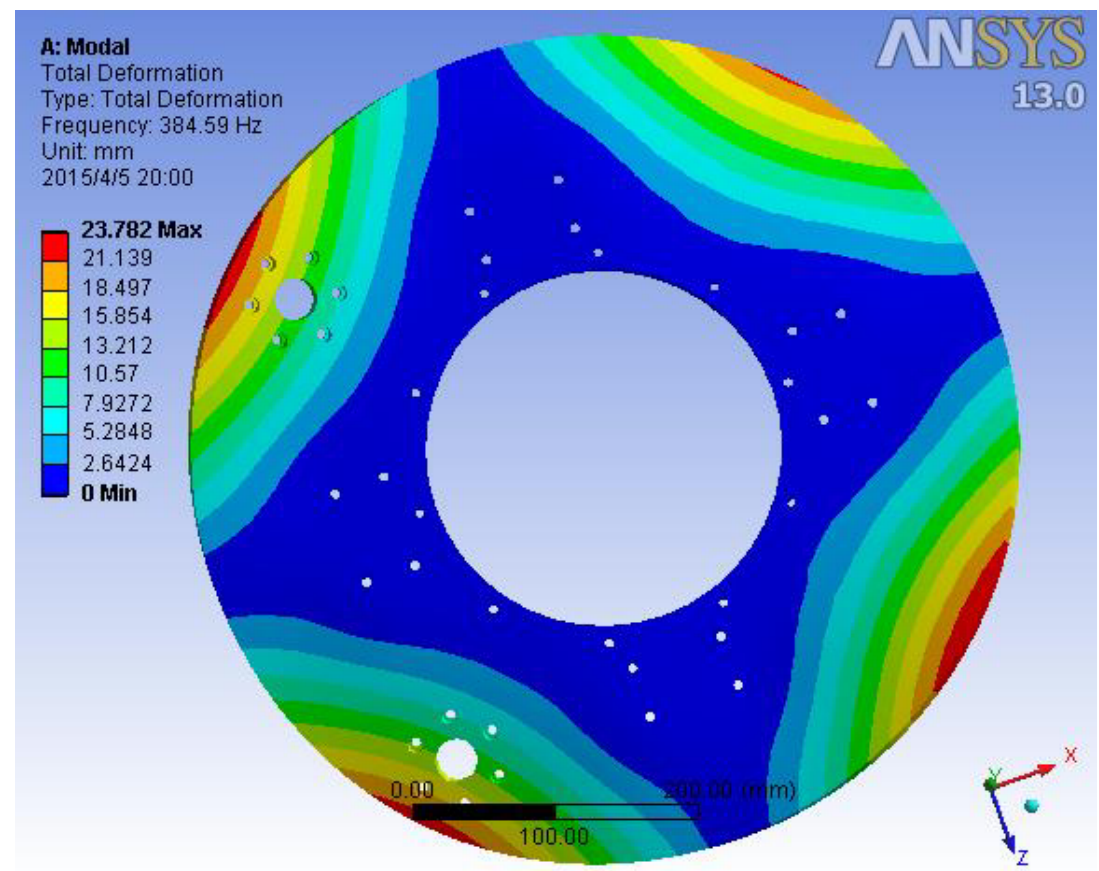

Figure 8. First order modal after lightweight

mation of moving platform according to finite element analysis and provided a theoretical basis for the design

(3) The thesis had compared two different structures through the analysis, and chosen structure 2 which had lighter weight and higher stiffness.

(4) It had obtained the inherent frequency and mode shape through model analysis. It had made sure that moving platform's inherent frequency was higher than the requirement frequency which led to resonant vibration and proved that the lightweight design was reasonable by comparing the results from the analysis.

(5)It had had important guiding significance to confirm the stress and weakness of up-platform through the analysis of ANSYS.

\section{REFERENCES}

[1] Jiang Huilin. \& Hu Yuan, 2012. Optical Principle Research of Space Laser Communication Network, Acto Optica Sinica, 32(10):1006003-1-1006003-3.

[2] Editorial committee of manual lifting machinery design. Manual lifting machinery design. China Machine Press. 1987.

[3] Yan Yong, Jing Guang. \& Yang Hongbo. 2008. Lightweight Structural Design of Space Mirror, Infrared and Laser Engineering, 37(1): 97-98.

[4] Bames W P. 1972. Hexagonal vs. triangular core lightweight mirror structures. Appl. Op., 11(12): 2748-2751.
[5] Li Long. 2013. Research on Laser Communication Stabilized Sighting Turntable for Vehicle Platform, Changchun University of Science and Technology.

[6] Sun Donghong, Guo Guanghai. \& Lin Aiming. 2004. Discussion on Some Problems of Helicopter Vibration Environment and Airborne Equipment Vibration Environment Test, Aeronautic Standardization \& Quality, 04:47-49.

[7] Wang Haipeng, Chen Wei. \& Zhao Zhenhua. 2004. Finite Element Complex Model Analysis by Using the ANSYS Workbench, ANSYS Chinese User Papers.

[8] Li Bin, 2007.The Structural Design and Optimization Simulation of Heavy-6-DOF Electric Swing Platform's Key Parts, HIT Harbin Institute of Technology.

[9] Xu Xiaodong, Xu Yanling. \& Zhang Bao. 2010. Discussion about optimization of ANSYS technology and its application in optimization design of mechanical structure, Rock Drilling Machine and Pneumatic Tools, (2). 